\title{
Evolução do Sistema Solar Primordial em Termos de Grande História e Evolução Universal
}

\author{
Leonid Grinin \\ Centro Eurasiático de Grande História e Previsão de Sistemas, \\ Instituto Oriental, Academia Russa de Ciências \\ Traduzido por Luis Brudna and Daniel de Pinho Barreiros
}

\section{Resumo}

A presente contribuição é dedicada a alguns aspectos da história e evolução do Sistema Solar primordial. A origem do Sol, da Terra, de outros planetas e dos seus satélites tem sido de grande interesse para as pessoas. Ao longo das últimas décadas, astrônomos e cosmólogos avançaram consideravelmente na percepção da estrutura, história e evolução do Sistema Solar. No entanto, dificilmente seríamos capazes de estabelecer propriamente uma narrativa; mais frequentemente trabalhamos com hipóteses. O presente artigo está estruturado da seguinte forma. Primeiro, descreve a história da formação do Sistema Solar nos primeiros cem milhões de anos de sua existência, quando as mudanças mais consideráveis ocorreram. Então, ao descrever certos processos formativos, mostramos as oportunidades para defini-los em termos de leis e regras evolutivas. Claro, este artigo apresenta apenas algumas dessas leis e regras. Acreditamos que o presente estudo seja de interesse para um leitor de duas maneiras. Em primeiro lugar, existem algumas pesquisas breves e consistentes sobre a história do Sistema Solar que contabilizam os últimos avanços em astrofísica e cosmologia. Além disso, eles são muito importantes e fecundos para teorizar parte da Grande História. Em segundo lugar, a discussão que emprega as leis e regras evolutivas gerais permite definir algumas características comuns na formação do Sistema Solar e especialmente do seu sistema planetário, que são características para cada nível e estágio da Grande História. Isso nos leva à ideia da integridade da Grande História não só em termos históricos e sistêmicos, mas também em relação à sua integridade na detecção de leis, padrões e mecanismos gerais.

\section{Palavras - chave}

sistema solar, exoplanetas, protonebulosa, sub-disco de pó, planetesimais, embriões de planeta, protoplanetas, catástrofes, migração planetária, regras e leis de evolução, desencadeamento, luta por recursos, sistemas primários.

Correspondence | Leonid Grinin, Леонид Гринин <leonid.grinin@gmail.com>

Citation | Grinin, L.. (2018) Evolução do Sistema Solar Primordial em Etermos de Grande História e Evolução

Universal. Traduzido por Luis Brudna <luisbrudna@gmail.com> and Daniel de Pinho Barreiros Journal of Big History, II(2); 115 - 127.

DOI | http://dx.doi.org/10.22339/jbh.v2i2.2305.g2175

\section{Introdução}

A presente contribuição é dedicada a alguns aspectos da história e evolução do Sistema Solar primordial, isto é, ao primeiro bilhão de anos de existência. Este período é crucial para entender como e por que o Sistema Solar se tornou o que conhecemos. Deve-se apontar que existem muitas hipóteses e teorias sobre a formação de planetas do Sistema Solar. Ainda nenhuma delas pode explicar toda a gama de problemas relacionados.

Este artigo é uma continuação do meu trabalho anterior (Grinin 2014) tanto no sentido do período abordado quanto em termos metodológicos. No meu artigo anterior (Ibid.) ett considerei os principais 
eventos da fase cósmica da Grande História a partir da Era Estrela-Galáxia, que descrevi em termos de princípios evolutivos universais. No presente trabalho, investigarei a evolução e a história do Sistema Solar primordial e, nesse contexto, vou mostrar a possibilidade de definir uma série de eventos desta história em termos de leis e regras evolutivas.

Esta abordagem foi deliberadamente escolhida, uma vez que permite amplificar a metodologia da Grande História com as realizações e os princípios da Evolucionística. Como escrevi em outro lugar, embora a Grande História ofereça oportunidades únicas para considerar o desenvolvimento do Universo como um processo singular, deve-se apontar que os estudos da Grande História tendem a atentar pouco para um aspecto tão importante como a unidade dos princípios, leis e mecanismos de evolução em todos os seus níveis. Eu acredito que combinar o potencial da Grande História com abordagens evolutivas pode abrir horizontes mais amplos a este respeito. $\mathrm{Na}$ verdade, os traços comuns em desenvolvimento, funcionamento e interação podem ser encontrados em diferentes processos e fenômenos dentro da Grande História. A este respeito, o caráter universal da evolução é expresso nas semelhanças objetivas que são detectadas em muitas manifestações em todos os seus níveis. Tal abordagem abre novas perspectivas para a nossa compreensão da evolução e da Grande História com suas forças motrizes, vetores e tendências e para criar um campo consolidado para uma pesquisa multidisciplinar (Grinin 2014, 163-164). Esta abordagem também produz um efeito sinérgico que revela novos aspectos do nosso Universo e da integridade do mundo.

Do ponto de vista evolutivo, eu dividi a história primordial do Sistema Solar em quatro grandes épocas.

A primeira época foi a formação do disco protosolar e protoplanetário a partir da nebulosa solar. Esta foi a época da formação da «ordem vinda do caos» nos termos de Prigogine e Stengers (1989) durando cerca de um milhão de anos após o colapso da nuvem protosolar.

A segunda época foi a formação de matéria sólida, embriões de planetas e planetas primários. Pode ser denotada como a época da luta pelos recursos - durando cerca de 10 a 50 milhões de anos após o colapso.

A terceira época pode ser chamada de época de migrações planetárias e catástrofes - durando cerca de 600 a 700 milhões de anos, cerca de 3,9 a 3,8 bilhões de anos atrás.

Finalmente, a arquitetura atual do Sistema Solar foi estabelecida.

A quarta época é chamada Intenso Bombardeio Tardio dos planetas e seus satélites por planetesimais e meteoritos que durou de 900 milhões a 3,2 bilhões de anos.

Conforme mencionado acima, a pesquisa sobre a evolução do Sistema Solar permitiu revelar um número significativo de processos e eventos que podem ser descritos em termos de leis e regras gerais de evolução. Na presente contribuição

eu tento mostrar que existem muitas semelhanças e características comuns manifestadas nos mais diferentes processos e fenômenos em vários estágios e níveis da Grande História.

Suponho que essa contribuição seja de interesse para os leitores de duas maneiras. Primeiro, existem algumas pesquisas consistentes e ainda breves sobre a história do Sistema Solar que contabilizam as últimas conquistas em astrofísica e cosmologia. No entanto, elas são muito importantes e produtivas para teorizar parte da Grande História. Em segundo lugar, a discussão que acompanha as leis e regras evolutivas gerais nos permite revelar alguns padrões na formação do Sistema Solar e especialmente do sistema planetário que são comuns para diferentes níveis e estágios da Grande História. Isso nos leva à ideia da integridade da Grande História não só em termos históricos e sistêmicos, mas também em relação à sua integridade na detecção das leis gerais, padrões e mecanismos.

Devido ao escopo do trabalho, escolhi as regras, leis e padrões evolutivos relacionados apenas a alguns eventos (e não todos) da história inicial do 
Sistema Solar (para detalhes, veja Grinin 2017a).

1. A formação do sistema protosolar a partir de uma nuvem de gás

Com respeito à história do Sistema Solar, ainda há mais hipóteses do que fatos comprovados. No entanto, ano após ano, as hipóteses relativas a certos fenômenos são corroboradas por observações diretas, por exemplo, como resultado da descoberta de numerosos exoplanetas.

A idade do Sistema Solar, determinada com a técnica de datação radioativa no estudo dos meteoritos mais antigos, é de aproximadamente 4,57 bilhões de anos (Shukolyukov e Lugmair 2003; Vityazev e Pecgernikova 2010, 168; Pfalzner et al. 2015). As principais características do sistema foram formadas durante os primeiros cem milhões de anos, mas a narrativa atual desse período ainda é extremamente fragmentada e pouco confiável.

Ao longo das últimas duas a três décadas, foi elaborado um chamado cenário padrão para a formação de um sistema planetário a partir de um disco protoplanetário de pó e gás que envolve uma protoestrela, o que permite definir os contornos gerais do processo.

Apoiado por numerosas observações diretas, o modelo do nascimento das estrelas geralmente é usado para reconstruir a origem do protosol. As estrelas geralmente são formadas nas partes mais densas de nuvens de poeira de gás molecular, esta última composta principalmente de hidrogênio e hélio e com uma temperatura próxima do zero absoluto. As nuvens de gás podem preservar o equilíbrio por muitos milhões de anos. É necessário um certo impulso (um gatilho) para iniciar o processo de condensação (e subsequente colapso). Talvez, para o nascimento do Sol, tal gatilho tenha sido a onda de choque de uma supernova próxima cerca de dois milhões de anos antes do início do colapso (Adushkin et al. 2008, 276).

Aqui lidamos com uma regra evolutiva geral que eu defini como uma regra de fenomenos ou eventos desencadeantes necessários para iniciar o processo evolutivo. Por um lado, dificilmente pode funcionar sem a prontidão interna de um sistema; e, por outro lado, mesmo uma prontidão interna de alto nível em si dificilmente pode garantir o início de uma transformação, assim como a pólvora não pode ser explodida sem fogo. Sem um gatilho, um sistema pode por muito tempo permanecer potencialmente pronto para transformações e ainda assim não ocorrerá nenhuma alteração.

A regra acima mencionada funciona em todos os níveis evolutivos. Por exemplo, há uma hipótese bem fundamentada sobre o papel do resfriamento que ocorreu há 6-8 milhões de anos e levou à formação de grandes espaços abertos na África Oriental. Isso promoveu a evolução dos hominídeos denominados Dryopithecus que viviam em árvores para hominídeos de andar bípede ereto dos Australopithecus ou de outro tipo (Kessler 2017; Niemitz 2010).

$\mathrm{Na}$ evolução social, o fenômeno desencadeante seria necessário para a formação de um estado inicial. Além do aumento da complexidade interna de um governo e da estratificação social, um gatilho também é necessário na forma de uma mudança abrupta na sociedade. Este último pode ter sido uma guerra, um reassentamento involuntário ou a abertura da tal sociedade ao mundo exterior (como aconteceu com os havaianos no final do século XVIII com a descoberta das ilhas por James Cook, veja Grinin 2017b).

Juntamente com a condensação da nuvem de gáspoeira, começa uma contração, ou uma queda livre controlada pela autogravidade, que, segundo algumas hipóteses, durou dez mil anos (Marove et al. 2008, 225; Motoyama Kazutaka e Tatsuo Yoshida 2003). O colapso em curso fez o fragmento inicial da nebulosa quebrar em grupos menores, de modo que geralmente pode gerar muitas estrelas. A condensação contínua dentro do aglomerado faz com que sua matéria se concentre gradualmente, preparando assim uma transformação em uma protoestrela. A contração é acompanhada por aquecimento, enquanto a estrutura da futura estrela é formada, incluindo seu núcleo e camadas. $\mathrm{O}$ centro da protoestrela se aquece gradualmente.

Após a formação dos núcleos externo e interno 
do protosol, o resto da matéria periférica rumou parcialmente ao núcleo e adicionou-se à massa da estrela em formação. Este processo de queda da matéria (no caso de um protosol - de gás) na superfície de um corpo é chamado de acreção. Depois que a camada de acreção essencialmente vai para a protoestrela, esta se transforma em uma jovem estrela. Enquanto isso, sua temperatura interna atinge vários milhões de graus, o que inicia reações termonucleares. A formação do Sol como uma estrela deve levar cerca de um milhão de anos, mas há estimativas prolongando ou reduzindo este período de tempo.

2. A formação dos corpos protoplanetários, embriões de planetas e protoplanetas

O disco protoplanetário e sua evolução. Durante a formação de uma estrela jovem, um disco circunstelar é muitas vezes formado visível através de comprimentos de onda ópticos e curtos. A matéria restante do disco de acreção é parcialmente dispersa no espaço, bem como usada na formação de um disco protoplanetário. De acordo com as observações, esse disco em torno das estrelas existe de 5 a 25 milhões de anos.

A dificuldade na reconstrução do processo de formação planetária para o Sistema Solar é compensada por um grande número de hipóteses e teorias que foram desenvolvidas ao longo de dois séculos. Mas nenhuma das hipóteses pode explicar toda a gama de fatos relacionados aos planetas até agora.

No entanto, a grande maioria dos cosmólogos acredita que o Sol e os planetas foram formados a partir de uma única nuvem (nebulosa protosolar) cuja matéria se diferenciou no Sol e no envelope protoplanetário, o último evoluindo para um disco como resultado da rotação. A rotação e a fragmentação deste disco protoplanetário formaram os planetas ao longo de um novo ciclo de acumulação de matéria em corpos protoplanetários. A maioria dos cosmólogos procede da ideia de que os planetas foram formados a partir de material frio, que foi mais tarde aquecido por onda de choque, radioatividade e outros processos. A formação de um disco protoplanetário acredita-se durar de um a vários milhões de anos. A massa do disco protoplanetário é estimada entre 3 e $10 \%$ da massa solar. Além disso, era distribuído espacialmente e heterogeneamente. As dimensões dos discos de acreção das estrelas jovens são de 100 a 1000 unidades astronômicas.

$\mathrm{O}$ disco era mais aquecido em suas partes internas, enquanto suas regiões externas permaneceram relativamente frias. Ocorreram algumas contrações, o que contribuiu para o surgimento de centros gravitacionais separados de formação planetária. Ainda assim, o mecanismo desse processo era extremamente controverso.

\section{A formação de um subdisco de poeira.}

Aparentemente, o disco protoplanetário era composto do gás da nuvem protosolar com predomínio absoluto do hidrogênio molecular e do hélio (todas as outras substâncias equivaliam a menos de 1\%). As partículas de poeira, apesar de representar 0,5 a $1,5 \%$ de massa, desempenharam um papel peculiar. Esta poeira era como formada por partículas sólidas microscópicas (gelo de água, moléculas pegajosas e átomos, em particular ferro e outras matérias sólidas). Como resultado da formação do protosol que acumulou a maior parte do gás, a concentração de poeira no disco protoplanetário aumentou na fase posterior da sua evolução. Mas, ainda mais, começou a aumentar como resultado da acreção de poeira no plano medial do disco.

Alguns cosmólogos acreditam que a forma mais provável de formação dos embriões planetários é através da acreção de partículas de poeira no plano equatorial do disco pré-planetário (Zasov e Postnov 2011, 199). Como resultado, um subdisco de gás de poeira foi formado no centro do disco, mas a razão entre poeira e gás já variou muitas vezes em comparação com o espaço circundante. Os grãos de poeira também podem aumentar de tamanho (devido a adesões e arrastes). Assim, o potencial sistema planetário passou por uma transição muito importante envolvendo a concentração de matéria 
sólida (até agora sob a forma de poeira), que desempenhou um papel essencial no crescimento de corpos pré-planetários e posteriores planetas. De acordo com alguns modelos, o disco protoplanetário quase solar evoluiria por um a dois milhões de anos antes da formação de um subdisco enriquecido com poeira.

Na verdade, o subdisco de poeira era comparativamente fino e sua espessura era 103 a 104 vezes menor do que o seu raio. Tinha que ser opaco para os raios do Sol e, portanto, não alcançavam a periferia do disco. Entre outras coisas, isso determinou as condições variáveis para a formação de planetas, dependendo da proximidade com o protosol.

Aqui lidamos com a regra evolutiva geral $d a$ importância da heterogeneidade e das flutuações . Neste contexto, o pó pode ser considerado como um elemento de heterogeneidade nas nuvens de hidrogênio molecular. E a concentração desta matéria sólida lançou o surgimento de corpos protoplanetários e, mais tarde, de planetas.

Em todos os níveis da Grande História, a mudança evolutiva requer a presença de heterogeneidade crítica que pode desencadear o reagrupamento de matéria ou elementos na reunião. E uma nova estrutura e ordem surgem nessa base. Além disso, uma homogeneidade absoluta torna impossíveis os processos evolutivos.

Por exemplo, uma mutação pode desencadear a especiação; considerando que os grupos de estrangeiros podem desempenhar um papel importante na transformação de muitos grupos étnicos e Estados iniciais.

\section{A formação iniciada de corpos pré- planetários.}

Como alguns cosmólogos supõem, por algum tempo, devido à gravidade e turbulência, o subdisco pode ter se contraído enquanto as condensações de poeira e gás e outros agregados podem ter sido formadas dentro dele. Mas o ponto de discussão é se os planetas foram formados a partir desses aglomerados de poeira e gás (como mantém a teoria da condensação) ou já de matéria sólida. A teoria da formação de planetas a partir de matéria sólida é chamada de teoria da acreção sucessiva. Muitos, se não a maioria dos cosmólogos, consideram o cenário mais provável.

De acordo com isso, as pequenas partículas de poeira se juntam, primeiro formando pequenas partículas de matéria sólida e, em seguida, objetos maiores que gradualmente cresceram em embriões planetários. As partículas de matéria sólida (de poucos a vários quilômetros ou mesmo mil quilômetros) são chamadas de planetesimais.

O estágio mais importante no processo de formação de embriões planetários é a formação de grandes (inteiros) corpos sólidos - planetesimais. Todas as teorias e hipóteses concordam neste ponto. No entanto, em relação ao número, tamanho e outras dimensões desses objetos grandes, há discrepâncias consideráveis. Existem estimativas diferentes do tamanho limite (crítico para o processo) dos planetesimais. Os proponentes da teoria da acreção sucessiva de matéria por planetesimais consideram hipoteticamente a formação de milhões e bilhões de corpos de tamanho de um quilômetro, que aumentam gradualmente no processo de enxameamento.

De acordo com a teoria da condensação, os maiores objetos podem atingir um tamanho de mil quilômetros.

Entre muitas forças que influenciaram a concentração e acumulação de matéria, a transformação da matéria da protonuvem em objetos sólidos, determinação de órbitas e, em geral, a formação protoplanetária, reconhece-se que duas forças desempenham um papel fundamental na formação planetária: gravidade e radiação solar. $\mathrm{E}$ ambos dependem diretamente da distância do objeto em relação ao Sol. Entre as órbitas de Marte e Júpiter, entre 2 e 4 AU do Sol, existe um limite teórico chamado linha do gelo, ou uma linha de neve. A linha do gelo é o local onde a água transita do estado de vapor para o estado sólido, uma vez que a intensidade da radiação solar diminui com a distância das estrelas. "No local onde a temperatura é 
160-170K, de modo que a água tenha uma transição do vapor para o estado sólido, as moléculas de água tendem a se acumular à medida que liberam resíduos" (Lin 2008, p. 53). A linha do gelo se transforma em um aglomerado de gelo que promove a criação de planetesimais.

Formação de grandes planetesimais. Quando as massas de planetesimais aumentam, sua gravidade permite que elas atraiam partículas próximas. Assim, numerosos planetesimais de quilômetros [de tamanho] captam ativamente o pó primário. Seu crescimento trouxe o surgimento dos enxames dos denominados planetesimais protoplanetários. Gradualmente, emergiu uma "elite" de poucos, composta de corpos do tamanho da Lua ou mesmo de Mercúrio. Existem muitas hipóteses quanto aos mecanismos de sua geração, bem como o número (de vários a cem). Ao longo do tempo, as órbitas dos maiores corpos tornaram-se circulares, o que os fez centros de atração para a matéria envolvente, tornando-se assim os embriões planetários. De acordo com os cálculos, a formação de planetesimais durou de dezenas a centenas de milhares de anos, enquanto a formação de corpos protoplanetários de planetesimais levou vários milhões de anos.

Hipóteses sobre os planetesimais em crescimento e a luta pelos recursos. Os planetesimais cresceriam devido à acreção de matéria, incluindo gás, bem como à atração mútua e colisões acidentais. Mas quanto maior é o planetesimal, mais forte é a sua gravidade e, de forma mais intensa varre seus vizinhos de pouca massa. Quando as massas de planetesimais individuais se tornam comparáveis à massa da Lua, a gravidade aumenta significativamente de modo que eles se tornam capazes de resvalar nos corpos circundantes, escapando das colisões. Como resultado da luta, confrontos e fusões, um pequeno número de grandes corpos cósmicos são formados, chamados de embriões planetários que dominam em suas zonas orbitais e lutam pela matéria restante.

Ao mesmo tempo, os planetesimais crescentes colidem constantemente $\mathrm{e}$, às vezes, fundem-se ou pelo contrário, se separam após choques. As numerosas divisões permitiram que os corpos maiores capturassem mais e mais recursos. Os objetos já grandes o suficiente continuaram a crescer. Gradualmente, os processos de auto-organização começaram a prevalecer neste caos.

Aqui lidamos com a regra evolutiva geral da luta por recursos e espaço vital. A luta pelos recursos é um mecanismo comum de seleção em todos os níveis de evolução. A luta pelos recursos é um componente importante da luta darwiniana pela existência no mundo biológico e da competição econômica humana. As vantagens, inclusive as acidentais, desempenham um papel importante em todos os níveis de seleção evolutiva. Sobre a lei da luta pelos recursos, veja também abaixo.

\section{Formação do sistema protoplanetário}

Problemas e hipóteses da formação de grupos planetários. A maioria dos pesquisadores acredita que o período anterior à formação dos primeiros planetas tenha durado pelo menos vários milhões de anos. Mas as discrepâncias na determinação de sua duração são bastante consideráveis, dependendo se os pesquisadores consideram a formação dos planetas do Sistema Solar como um processo simultâneo ou acontecendo em momentos diferentes. No entanto, até recentemente, a ideia comum foi que todos os planetas foram formados mais ou menos ao mesmo tempo. Atualmente, mais cientistas tendem a acreditar que os planetas surgiram em momentos diferentes, e os intervalos entre suas formações poderiam chegar a milhões ou dezenas de milhões de anos.

Assim, alguns estudiosos pensam que foi Júpiter que veio primeiro, depois Saturno, e muito mais tarde os planetas terrestres foram formados (ver, por exemplo, Lin 2008; Savchenko e Smaghin 2013; Christian 2004, 60 com referência a Taylor 2002, 59-60); ainda outros acreditam que os planetas do grupo da Terra surgiram primeiro (veja, por exemplo, Marakushev et al. 2013; Vityazev et al. ) Alguns estudiosos acham que, em primeiro lugar, os planetas 
terrestres eram semelhantes aos planetas gigantes, mas depois perderiam seus envelopes fluidos (ver, por exemplo, Marakushev e Zinovieva 2013, Yazev 2011, 357).

Há também uma ideia interessante de que existe não uma, mas duas ou mesmo mais gerações de planetas primários. Existe uma opinião de que, não sendo formados adequadamente, esses planetas primários explodiram e geraram o cinturão de asteroides. Ainda outros pensam que Júpiter e Saturno podem ter empurrado os planetas primários para o Sol ou os expelido do Sistema Solar. Assim, teve lugar mais do que uma tentativa de formar a ordem atual dos planetas no Sistema Solar.

Aqui lidamos com a regra do caráter arcaico dos sistemas primários. Isso se refere a planetas primários ou estrelas, bem como a espécies biológicas primárias ou digamos, a estados prístinos (sobre o último ver Grinin 2008). Os sistemas não são formados maduros e estáveis. Eles geralmente sofrem várias reconfigurações, incluindo os ciclos de destruição e recriação. É por isso que os sistemas primários costumam parecer arcaicos, enquanto os sistemas superiores emergem como secundários ou terciários e têm mais oportunidades de autorregulação. Consideremos as primeiras estrelas que surgiram no máximo te 200 a 400 milhões de anos após o Big Bang (por exemplo, veja European Commission 2011). É aceito que as primeiras estrelas eram gigantes, muito mais maciças do que a maioria das estrelas formadas posteriormente (May et al. 20 Devido à ausência de carbono, oxigênio e outros elementos que absorvem energia de nuvens condensantes, o processo prosseguiu mais lentamente naquela época; assim, apenas nuvens gigantes poderiam se condensar para produzir estrelas maciças centenas vezes maiores do que o Sol (Ibid.). Essas estrelas gigantes viviam apenas por alguns milhões de anos (quanto maior é uma estrela, menor é a sua vida). Além disso, as primeiras estrelas continham uma pequena quantidade de elementos pesados. Assim, mais de uma geração de estrelas poderia ter mudado até que a quantidade de elementos pesados aumentasse gradualmente. $\mathrm{O}$ surgimento de elementos pesados dos "restos estelares das estrelas mortas" assemelha-se à formação de solo fértil dos restos de plantas mortas. A circulação da matéria no Universo sempre é observada em todos os lugares e em todos os níveis (esta é outra lei evolutiva, a respeito da qual veja Grinin 2013, 2014).

As causas das diferenças nos modelos de formação de planetas gigantes e terrestres. Como os planetas do Sistema Solar são divididos em duas categorias (terrestres e gigantes gasosos), o problema da diferença de seus padrões de formação se torna essencial. Esta formação era fundamentalmente a mesma em ambos os grupos, enquanto as diferenças eram determinadas pela distância do Sol, ou o processo de formação de diferentes grupos de planetas era essencialmente diferente, ou ainda existiam outras combinações?

Não há dúvidas de que a distância do Sol definiu as peculiaridades dos modelos de formação do planeta. Diferentes períodos orbitais de embriões planetários (quanto mais longe o planeta está do Sol, maior a órbita) produziram oportunidades para a captura de planetesimais circundantes e, respectivamente, o raio e a massa de um protoplaneta. A linha de neve efetuou uma maior concentração de planetesimais e matéria em certas regiões do Sistema Solar, que também poderia definir o tamanho dos planetas em diferentes regiões.

Existem inúmeras hipóteses que explicam a origem das categorias de planetas observadas. Por exemplo, há argumentos de que os gigantes gasosos provavelmente foram os primeiros planetas a se formar e tomar quase todo o gás, enquanto os planetas do tipo da Terra obtiveram poucos recursos.

Aqui voltamos a lidar com a lei de luta por recursos e observamos que a distribuição de recursos no mundo cósmico é na mesma medida injusta como nos reinos sociais e biológicos. Por exemplo, a luta por recursos que, entre estrelas e galáxias, podem prosseguir sob a forma de enfraquecimento de outro objeto ou sua destruição (por exemplo, através de uma transferência direta de energia e matéria de um corpo para outro), sob a forma de 'incorporação', 'captura', que é ‘anexação' de estrelas e aglomerados 
de estrelas por grupos maiores. Existem muitos casos de coalescência galáctica. Assim, alguns astrônomos afirmam que durante alguns bilhões de anos a nossa galáxia 'conquistou, roubou e rendeu' centenas de galáxias pequenas, pois existem alguns 'imigrantes' evidentes na nossa galáxia, incluindo a segunda estrela mais brilhante no céu do norte, Arcturus (Gibson e Ibata 2007, 30). É amplamente aceito que o surgimento e a expansão de um buraco negro pode levar à "alimentação" de matéria das estrelas e galáxias próximas. No entanto, a 'capacidade alimentar' dos buracos negros é muito exagerada na literatura popular. Em sistemas de estrelas duplas ou em sistemas estrela-planeta, também se pode observar uma forma de interação como a troca de energia e recursos (sobre a luta cósmica pelos recursos, ver também Grinin 2013, capítulo 5).

\section{Hipóteses e teorias sobre os planetas internos.} Existem três abordagens principais para a formação de planetas terrestres.

1) A massa do planeta aumenta até o tamanho do presente através do acúmulo de planetesimais (e meteoritos), o que resulta em uma separação gradual do interior do planeta em núcleo, manto e crosta (não em todos os planetas).

2) A formação dos planetas terrestres seguindo o padrão do planeta gigante. No entanto, mais tarde, os planetas terrestres perderam gases no espaço. Respectivamente, apenas seus núcleos internos de ferro-níquel e silicato permaneceram. Assim, os núcleos de silicato e ferro desses protoplanetas gigantes se transformaram em pequenos planetas independentes. A estratificação em núcleos de ferro e fortes camadas de silicatos impediu sua desintegração explosiva (Marakushev et al. 2013, 135-37).

3) O impacto de Júpiter e Saturno na formação dos planetas terrestres (ver abaixo).

Hipóteses e teorias sobre os planetas externos. A teoria da formação planetária presta especial atenção a dois planetas gasosos gigantes que representam $92 \%$ da massa de todo o sistema planetário (isto é, Júpiter e Saturno, mas especialmente Júpiter).

Existem duas hipóteses principais que descrevem os possíveis padrões de formação de Júpiter e Saturno compostos principalmente por hidrogênio e hélio. A primeira hipótese da contração explica a composição gasosa dos planetas gigantes pelo fato de que as condensações maciças de gás-poeira protoplanetas - foram formadas dentro de um enorme disco protoplanetário, que mais tarde no processo de compressão gravitacional se transformaria em planetas gigantes. No entanto, esta hipótese não explica por que a composição de Júpiter e Saturno difere da do Sol, bem como alguns outros problemas.

De acordo com a segunda hipótese de acreção, a formação de Júpiter e Saturno passou por duas etapas. Na primeira fase, os corpos sólidos foram acumulados de forma semelhante aos processos com planetas terrestres e, após a massa dos maiores corpos atingiram um valor crítico (de duas a dez e mais massas terrestres), a segunda etapa implicaria a acreção de gás nestes já bastante enormes corpos que ocorreram em uma escala de tempo de 105-106 anos. Na primeira fase, um pouco de gás da região de Júpiter se dissipou, de modo que sua composição seria diferente da solar, e isso era ainda mais evidente na formação de Saturno.

De acordo com a concorrente hipótese de contração, a temperatura dos planetas gigantes também foi alta no estágio inicial, mas a dinâmica dos processos provou ser mais razoável dentro da hipótese de acreção. A formação de Urano e Netuno, que contém menos hidrogênio e hélio, também é melhor explicada pela hipótese de acreção, já que a maioria do gás já saiu do Sistema Solar depois de atingir a massa crítica.

Ainda assim, o processo de formação do planeta é bastante lento devido à acreção no núcleo. Pode demorar vários milhões de anos. Alguns pesquisadores, além do cenário de acreção no núcleo, também consideram que a instabilidade gravitacional em regiões densas e frias do disco pode levar à formação de planetas. A formação de planetas devido à instabilidade gravitacional pode levar muito menos tempo do que pode exigir quando são formados por acreção no núcleo. Há também uma hipótese que sugere que os gigantes gasosos são formados 
por um colapso súbito, levando à destruição da nuvem primária de gás e poeira. Mas a maioria dos cosmólogos nega a possibilidade de colapso gravitacional para planetas por causa de suas massas relativamente pequenas (reconhecendo-o apenas para as estrelas).

\section{A migração planetária}

Como se pensava anteriormente, os planetas permaneciam nas órbitas originais desde a sua formação. Mas, recentemente, tornou-se popular a opinião de que levou aos planetas cerca de um bilhão de anos para ocupar as órbitas atuais. Na sua história inicial, o Sistema Solar era diferente, e é bastante provável que o Sistema Solar externo fosse muito mais compacto, enquanto o cinturão de Kuiper estava localizado mais perto do Sol. Existem muitas sugestões sobre migrações de planetas; ainda, estas são apenas hipóteses.

\section{A mudança da órbita de Júpiter e outros}

planetas. Há especialmente muitas sugestões sobre as migrações de Júpiter e Saturno. De acordo com uma delas, este gigante gasoso deve ter se formado dentro da parte interna do sistema planetário, perto da linha de neve, quando ainda havia uma quantidade considerável de gás no disco. Então, teve que se mudar para sua órbita atual (Lin 2008). Quando Júpiter deslocou-se para o Sol arrastando Saturno, funcionou como um trator gravitacional, "puxando" várias massas terrestres de gelo no sistema (Batygin et al. 2016). Há uma hipótese de que cerca de 600 a 700 milhões de anos após a formação do Sistema Solar, Júpiter começou a vagar e entrou em ressonância orbital com Saturno. A ressonância mudou as órbitas desses planetas, uma vez que abrandou a migração para dentro e enviou-os de volta para a parte externa do Sistema Solar. A ressonância afetou muito todo o Sistema Solar. Em particular, Netuno e Urano trocaram as órbitas uma vez que Urano costumava ocupar uma posição mais distante do Sol do que Netuno (Ibid.,veja também Batygin e Brown 2016).
Levou algum tempo para que os planetas saíssem de ressonância. Ao longo de alguns milhões de anos, a interação caótica entre gigantes instáveis "empurrou" Júpiter para o seu lugar atual, e outros planetas "se afastaram". Além disso, de acordo com uma das hipóteses exóticas no decurso dessa reconfiguração, um dos gigantes pode ter sido expulso para o espaço interestelar. Aqui queremos dizer o nono planeta hipotético que pode ter existido no passado distante. Aqui, lidamos novamente com a regra do caráter arcaico dos sistemas primários segundo a qual são necessárias algumas grandes mudanças (talvez, mesmo ciclos de mudanças) antes que um sistema encontre seu equilíbrio.

Além disso, a chamada era do intenso bombardeio tardio ou, mais precisamente, certa parte dessa época, provavelmente está associada a esse evento de ressonância (ver Bottke et al. 2012, Gomes et al. 2005). Uma imensa quantidade de precipitação de meteoritos caiu em planetas rochosos durante esse período tardio. Estudos relativamente recentes mostraram que esta foi uma era longa, que terminou a 3,2 bilhões de anos, ou seja, durou quase um bilhão de anos.

\section{Colisões e catástrofes na história inicial do} Sistema Solar. As mais debatidas são as duas supostas catástrofes que ocorreram durante os primeiros cem milhões de anos. A primeira foi a colisão de Vênus com Mercúrio. Vênus tem uma rotação retrógrada (contra a rotação do Sol em torno de seu eixo) enquanto a maioria dos outros grandes corpos no Sistema Solar rodam na mesma direção com o Sol. Mercúrio possui um núcleo de níquel-ferro não proporcional, uma vez que o seu núcleo metálico equivale a 60 ou mais por cento de sua massa total (Solomon 2003). Existem várias explicações possíveis aqui. Uma afirma que isso pode ser o resultado de uma colisão de Mercúrio com um grande asteroide e, como resultado desse impacto tangente, Mercúrio perdeu a maior parte de seu manto e crosta (Yazev 2011, 48). Há também uma alternativa mais exótica, de que Mercúrio estava inicialmente mais longe do Sol e, além disso, não era um planeta, mas um satélite de Vênus, do qual mais 
tarde "escapou". Isso explica o tamanho pequeno de Mercúrio, mais apropriado para um satélite, e a rotação retrógrada de Vênus. A teoria dominante aqui é o efeito de maré de um grande satélite (isto é, de Mercúrio) que, há muito tempo, retardava o movimento orbital do planeta e até o fazia girar na direção retrógrada (Ibid., 57-58).

Outra hipótese famosa em relação a catástrofes é a ideia de que entre 30 e 100 milhões de anos após a formação do Sol, um embrião de planeta do tamanho de Marte colidiu com a proto-Terra e gerou uma enorme quantidade de detritos que posteriormente formaram a Lua. Esta tese tem várias alternativas. Existe uma hipótese fascinante de que, por milhões de anos, um protoplaneta Theia pode ter orbitado próximo da proto-Terra e finalmente colidiu com ela. Acredita-se que a colisão tenha ocorrido quase tangencialmente e em uma velocidade relativamente lenta. É por isso que parte do manto da Terra e de Theia foram ejetados para a órbita terrestre baixa e, a partir desses detritos, formou-se a Lua que começou a girar ao longo da órbita circular.

Mais hipóteses sobre colisões. Mencionamos acima que cerca de 600 a 700 milhões de anos após o colapso da nebulosa protosolar Netuno migrou para uma nova órbita. Recentemente, uma hipótese foi apresentada de que não haviam quatro, mas cinco planetas gigantes no Sistema Solar, e que o quinto planeta colidiu com o Netuno migratório e o puxou para a atual órbita enquanto o quinto planeta gigante entrara em colapso em um aglomerado de detritos que Netuno lançou no cinturão de Kuiper, isto é, nos arredores do Sistema Solar (Taylor Redd 2015; Nesvorný 2011).

Aqui lidamos com um padrão evolutivo amplamente difundido - o de catástrofes. Podese apontar que o drama é característico da Grande História em todas as suas etapas. Em particular, uma hipótese famosa afirma que a extinção do Cretáceo-Paleogeno foi causada pelo impacto de um asteroide em Yucatã há cerca de 65 milhões de anos (Harmon 2010). Além disso, as catástrofes também afetaram consideravelmente o curso da evolução social. Deixe-nos dar o exemplo da Peste Negra na Europa do século XIV. As catástrofes são um dos principais mecanismos de seleção em todos os níveis da Grande História. Elas podem servir como disparadores, lançando alguns processos, além de destruir os sistemas defeituosos e expandir as oportunidades evolutivas para aumentar a variabilidade.

Cerca de 3,8 bilhões de anos, os gigantes estabeleceram suas órbitas atuais. Considera-se que, após o estabelecimento da ordem atual dos planetas e satélites, não houve mudanças consideráveis no Sistema Solar. Grandes mudanças ocorreram com os próprios planetas e em sua estrutura geológica, clima, composição da atmosfera e outras características.

\section{Conclusão}

Agora, podemos resumir as regras, leis e padrões de evolução acima descritos:

- a regra da necessidade de desencadear fenômenos ou eventos para iniciar o processo evolutivo; - a regra da importante heterogeneidade e flutuações; - a lei da luta pelos recursos e pelo espaço vital; - a regra do caráter arcaico dos sistemas primários; - catástrofes como mecanismo essencial de seleção.

Mas estas são apenas algumas regras e leis evolutivas. No entanto, muito do que sabemos sobre tendências, padrões e mecanismos que influenciaram as transformações dentro da Grande História, bem como leis evolutivas, as regras podem ser rastreadas já em sua fase cósmica. Às vezes, de forma incipiente e não sistêmica, ou pelo contrário, as manifestações mais vivas podem ser encontradas apenas na fase cósmica. Assim, quando várias características e padrões típicos da evolução biológica e social (por exemplo, como a luta pelos recursos) são observadas inesperadamente em fases anteriores da Grande História, começamos a perceber que o caráter universal da evolução é uma realidade com numerosas manifestações.

\section{Referências}

Adushkin, Vitaly V., Andrey V. Vityazev, and Galina Pechernikova, "To the Elaboration of the 
Theory of the Origin and Early Evolution of the Earth", in Issues of the Origin and Evolution of the Biosphere, ed. Eduard Galimov (Moscow: LIBROKOM, 2008), 275-296. In Russian (Адушкин, В. В., Витязев, А. В., Печерникова, Г. В. В развитие теории происхождения и ранней эволюции Земли. Проблемы зарождения и эволюции биосферы: сб. науч. работ / под ред. Э. М. Галимова, с. 275-96. М.: ЛИБРОКОМ).

Batygin, Konstantin and Michael E. Brown, «Evidence for a Distant Giant Planet in the Solar System,» The Astronomical Journal 151(2) (2016): 22. URL: http://stacks.iop. org/1538-3881/151/i=2/ $\mathrm{a}=22$.

Batygin, Konstantin, Gregory Laughlin, and Alessandro Morbidelli, «Born of Chaos,» Scientific American 5 (314) (2016): 28-37. doi:10.1038/ scientificamerican0516-28.

Bizzarro, Martin et al. «Evidence for a Late Supernova Injection of $60 \mathrm{Fe}$ into the Protoplanetary Disk,» Science 316(5828) (2007): 1178-1181. doi:10.1126/science. 1141040.

Bottke, William F et al. «An Archaean Heavy Bombardment from a Destabilized Extension of the Asteroid Belt,» Nature 485 (7396) (2012): 7881. doi:10.1038/nature10967.

Christian, David. Maps of Time: An Introduction to Big History (Berkeley: University of California Press, 2004).

Christian, David. «Swimming Upstream: Universal Darwinism and Human History» in Teaching and Researching Big History: Exploring a New Scholarly Field, ed. Leonid Grinin et al. (Volgograd, Russia: Uchitel Publishing House, 2014), 19-40.

European Commission, «EU Marie Curie researcher discovers galaxy 13 billion light years away,» MEMO 237 (2011). URL: http://europa.eu/rapid/ press-release_MEMO-11-237_en.htm.

Gibson, Brad, and Rodrigo Ibata, «The Phantom of Dead Galaxies,» V mire nauki, June (2007): 2935. In Russian (Гибсон Б., Ибата Р. Призраки погибших галактик. В мире науки, июнь: 29-
$35)$.

Gomes, Rodney, and others, «Origin of the Cataclysmic Late Heavy Bombardment Period of the Terrestrial Planets,» Nature 435 (7041) (2005): 466-69. doi:10.1038/nature03676.

Grinin, Leonid «Early State, Developed State, Mature State: Statehood Evolutionary Sequence,» Social Evolution \& History 7 (1) (2008): 67-81.

Grinin, Leonid. The Development of the World in terms of Big History: the Cosmic Evolution (Volgograd: Uchitel, 2013). In Russian (Гринин, Л. Е. Больш.ая история развития мира: космическая эволюция. Волгоград: Учитель).

Grinin, Leonid. «The Star-Galaxy Era of Big History in the Light of Universal Evolutionary Principles,» in Teaching \& Researching Big History: Exploring a New Scholarly Field, ed. Leonid Grinin, Leonid et al. (Volgograd: 'Uchitel' Publishing House, 2014), 163-187.

Grinin, Leonid. The Development of the World in terms of Big History: the History and Evolution of the Solar System (Volgograd: Uchitel, 2017a). In Russian (Гринин, Л. Е. Большая история развития мира: история и эволюция Солнечной системы. Волгоград: Учитель).

Grinin, Leonid. «Complex Chiefdoms: Precursor of the State or Its Analogue?» in Chiefdoms: Yesterday and Today, ed. Robert L. Carneiro, Leonid Grinin, and Andrey Korotayev (Clinton Corners - New York: Eliot Werner Publications, Inc., 2017b), 195-232.

Grinin, Leonid, and Andrey Korotayev, «Introduction. At the Junction of Theories and Paradigms,» in Evolution: Development within Big History, Evolutionary and World-System Paradigms, ed. Leonid Grinin and Andrey Korotayev (Volgograd: 'Uchitel' Publishing House, 2013), 5-17.

Gromov, Alexander. The Amazing Solar System (Moscow: EKSMO, 2012). In Russian (Громов А. Н. Удивительная Солнечная система. М.: ЭКСМО).

Harmon, Katherine. «A Theory Set in Stone: An Asteroid Killed the Dinosaurs, After All,» 
Scientific American, March 4 (2010). URL: https:// www.scientificamerican.com/article/asteroidkilled-dinosaurs/.

Kessler, Peter. «Prehistoric World: Hominid Chronology,» History Files, 26 (2017). URL: http://www.historyfiles.co.uk/FeaturesAfrica/ HominidChronologyl.htm.

Lin, Douglas N. C.. «The Genesis of Planets,» Scientific American 298(5) (2008): 50-59. doi:10.1038/scientificamerican0508-50.

Marakushev, Alexey A. and Nina G. Zinovyeva, «Meteorites and Planets of the Solar System,» Prostranstvo i vremya 4(1) (2013). URL: http://jspacetime.com/actual\%20content/t4v1/22279490e-aprovr_e-ast4-1.2013.11.php. In Russian (Маракушев, А. А., Зиновьева, Н. Г. Метеориты и планеты Солнечной системы. Пространство и Время. Т. 4. Вып. 1).

Marakushev, Alexey A. et al.»Origin and Evolution of the Solar System,» Prostranstvo $i$ vremya 2 (12) (2013): 132-141. In Russian (Маракушев, А. А., Зиновьева, Н. Г., Панеях, Маракушев, Н. А., С. А. Зарождение и эволюция Солнечной системы. Пространство и Время. Вып. 2 (12), с. 132-41).

Marov, Mikhail et al. «From a Proto-Solar Nebula toa Planatary Systam: The Model of the Emergence of the Gas-Dust Disk,» in Issues of the Origin and Evolution of the Biosphere, ed. E. Galimov, M. (ed.), (Moscow: Librokom, 2008), 223-274. In Russian (Маров, М. Я., Колесниченко, А. В., Макалкин, А. Б., Дорофеева, В. А., Зиглина, И. Н., Чернов, А. В. От протосолнечного облака к планетной системе: Модель эволюции газопылевого диска. Проблемы зарождения и эволюции биосферы: сб. науч. работ / под ред. Э. М. Галимова, с. 223-74. М.: ЛИБРОКОМ).

May,¡Brian, Patrick Moore, ‘and Chris Lintott, Bang: The Complete History of the Universe (Baltimore, MD: Johns Hopkins University Press, 2008).

Motoyama, Kazutaka and Tatsuo Yoshida, «High Accretion Rate during Class 0 Phase due to External Trigger,» Monthly Notices of the Royal
Astronomical Society 344 (2) (2003): 461-67. doi:10.1046/j.1365-8711.2003.06833.x.

Nesvorný, David. Young Solar System's Filth Giant Planet? The Astrophysical Journal 742(2) (2011): L22. doi:10.1088/2041-8205/742/2/L22.

Niemitz, Carsten. «The Evolution of the Upright Posture and Gait - a Review and a New Synthesis,» Naturwissenschaften. 97 (2010): 241-263. doi:10.1007/s00114-009-0637-3. PMC 2819487 Freely accessible. PMID 20127307 www. ncbi.nlm.nih.gov/pmc/articles/PMC2819487/

Prigogine, Ilya and Isabelle Stengers, Order Out of Chaos. Man's New Dialogue with Nature (Bantam Books, 1989).

Savchenko, Valery N. and Vladimir P. Smaghin. Conception of Modern Natural Studies. 2 vols. Vol. 2. Planetary, Chemical, Biological, Evolutionary, Philosophy and Methods, and Mega History of the Universe (Vladivostok: VGUES, 2013). In Russian (Савченко, B. Н., Смагин, В. П. Концепции современного естествознания: в 2 т. Т. 2. Планетное, химическое, биологическое, эволюционное, философия и инструменты, мегаистория Вселенной. Владивосток: Изд-во ВГУЭС).

Shklovsky, Igor S. Universe, Life, Mind (Moscow: Nauka, 1987). In Russian (Шкловский И. С. Вселенная, жизнь, разум. М.: Наука).

Solomon, Sean. «Mercury: the Enigmatic Innermost Planet,» Earth and Planetary Science Letters 216 (4) (2003): 441-455. doi:10.1016/S0012821X(03)00546-6.

Taylor, Ross. «The Solar System: An Environment for Life?» in To Mars and Beyond: Search for the Origins of Life, ed. Malcolm Walter (Canberra: Museu Nacional da Austrália, 2002), 59-60.

Taylor Redd, Nola . Our Early Solar System may have been Home to a Fifth Giant Planet. Science (Aug. 11,2015). doi:10.1126/science.aad1604. http://www.sciencemag.org/news/2015/08/ourearly-solar-system-may-have-been-home-fifthgiant-planet.

Vityazev, Andrey V., Galina V. Pechernikova, and Viktor Safronov, The Terrestrial Planets: Origin 
and Early Evolution (Moscow: Nauka, 1990).

In Russian (Витязев, А. В., Печерникова, Г.

B., Сафронов, В. С. Планеты земной группы:

Происхождение и ранняя эволюция. М .:

Наука).

Yazev, Sergey. Lectures on the Solar System: A

Textbook (St. Petersburg: Lan', 2011). In Russian

(Язев С. А. Лекции о Солнечной системе: уч. пособ. / Ред. В. Г. Сурдин. СПб.: Лань).

Zasov, Anatoly and Konstantin Postnov, The Course of General Astrophisics (Fryazino: Vek 2, 2011). In Russian (Засов, А. В., Постнов, К. А. Курс общей астрофизики. Фрязино: Век 2). 
